\title{
O Potencial das Narrativas para Favorecer a Evolução de Estratégias Diante de um Desafio Matemático Proposto a Licenciandos em Ciências
}

\author{
Wagner Marcelo Pommer ${ }^{1}$
}

\begin{abstract}
Resumo
Na interface entre a língua materna e a Matemática, este texto objetivou verificar se alunos ingressantes de um curso de Licenciatura em Ciências manifestam evolução de estratégias diante de um problema matemático proposto na forma de um desafio, enunciado em um contexto de narrativa. A metodologia de pesquisa inspirou-se na Engenharia Didática, descrita em Artigue (1996) e Machado (2002), aplicada a alunos de uma universidade pública em São Paulo. Os resultados revelaram que a narrativa, presente no enunciado do desafio, propiciou motivação para que os licenciandos em Ciências buscassem as soluções, a partir da utilização inicial da tentativa e erro. Houve também a diversificação de estratégias, implicitamente embasadas em propriedades de múltiplos e paridade, de modo gradual, simples e acessível. Os alunos de Licenciatura em Ciências pesquisados, no entanto, revelaram grande dificuldade na percepção e utilização da escrita algébrica como forma organizadora e otimizadora de resolução de problemas matemáticos.
\end{abstract}

Palavras-chave: Estratégias. Resolução de problemas. Desafio. Narrativas. Engenharia Didática.

THE POTENTIAL OF NARRATIVES TO FAVOUR STRATEGIES' EVOLUTION IN A MATHEMATICAL CHALLANGE PROPOSED TO SCIENCE LICENTIATE'S STUDENTS

\section{Abstract}

At the interface between Natural Language and Mathematics, this text aimed to verify if incoming students of Science Licentiate express evolution of strategies against a mathematical problem, proposed in the form of a challenge, and enunciated in a narrative context. The research methodology was inspired in Didactic Engineering, described in Artigue (1996) and

1 Doutorado em Educação Feusp. Mestrado em Educação Matemática PUC/SP. wagner.pommer@ unifesp.br 
Machado (2002), applied to students of a public university at São Paulo State. The results revealed that the narrative, present in the statement of the challenge, provided motivation for the science licenciate students to seek solutions, based on the initial utilization of trial and error. There was still the diversification of strategies, implicitly based on multiples and parity properties, in a gradual, simple and accessible way. However, the researched students of Science Licenciate have revealed great difficulty in the perception and utilization of algebraic writing as an organizing and optimizing way of solving mathematical problems.

Keywords: Strategies. Problem solving. Challenge. Narratives. Didactic Engineering,

Recebido em: 26/1/2017

Aceito em: 7/8/2017 
Pozo (1998) considera que a escola não pode se limitar a fornecer conhecimentos estanques aos alunos, em situações formais de ensino, mas deve prover condições para que o estudante exercite a aprendizagem, em situações e contextos diversos.

As Licenciaturas constituem-se como um espaço necessário e essencial para conciliar conteúdos e metodologias de ensino nas diversas disciplinas. Em particular, o professor de Matemática deve ter consciência do que se constitui a atividade matemática e quais as condições propícias para sua aprendizagem em sala de aula (D'Ambrosio, 1993).

As situações na escolaridade básica requerem dos alunos certas especificidades pertinentes ao universo da Matemática. De acordo com Passos e Oliveira (2005), nas aulas de Matemática a comunicação pode ocorrer “[...] em diferentes modalidades: forma de texto - linguagem materna ou linguagem matemática, tabelas, gráficos, obras de arte, imagem - visual ou pictórica, figuras geométricas" (p. 1).

No meio acadêmico e nas escolas são destacadas dificuldades de alunos com relação à leitura e interpretação de enunciados diante da resolução de problemas matemáticos, fato destacado em Passos e Oliveira (2005), Feriguetti e Lucas (2011) e Liel e Bortoli (2011).

É comum que as situações-problema abordadas em Matemática se constituam em um único parágrafo, geralmente contendo exclusivamente as informações justas e necessárias para o encaminhamento da(s) solução(ões). Se considerarmos como fonte os livros didáticos de Matemática, a apresentação mais comum se limita a:

[...] problemas estereotipados, onde também se distingue com nitidez os dados - sempre os necessários e suficientes para a resolução - dos pedidos a serem determinados com a utilização dos dados. Tanto o momento da formulação do problema, a partir de uma situação concreta onde a questão a ser respondida ainda não está nitidamente formulada, quanto a etapa do reconhecimento dos dados que serão necessários para a resposta a tal questão, 
costumam ser subestimados e simplificados excessivamente, fornecendo-se o problema pronto, bem formulado, às vezes, até equacionado, carecendo apenas da aplicação da "teoria” aprendida (MACHADO, 1996, p. 35-36).

A coordenação das diversas modalidades de registro inerentes à atividade matemática com elementos da língua materna pode trazer benefícios para a sala de aula. Tal opção de abordagem complementar é destacada nos Parâmetros Curriculares Nacionais, pois o ato de se comunicar utilizando:

[...] ao mesmo tempo elementos da língua materna e alguns símbolos matemáticos, são atividades importantes para que a linguagem Matemática não funcione como um código indecifrável para os alunos (BRASIL, 1997, p. 41- 42).

Liel e Bortoli (2011), ao realizar um extenso levantamento bibliográfico envolvendo a pesquisa na área de resolução de problemas, constataram que o desempenho menor ocorre em situações nas quais se utiliza uma linguagem matemática mais formal e sintática. Os autores também identificaram que as dificuldades dos alunos não estão ligadas exclusivamente à falta de conteúdo, mas podem ser contornadas quando se utilizam situações contextualizadas priorizando a exploração de procedimentos, ao invés de se ater a algoritmos, ou ao se estimular a avaliação crítica das respostas obtidas nas atividades matemáticas, por meio da articulação entre atividades de ensino e aprendizagem, o que viabilizaria a construção de modelos mentais.

Considerando-se a resolução de problemas em Matemática, a primeira etapa para enfrentá-los requer a leitura e a compreensão do texto. Esta etapa inicial de resolução de problemas propicia uma interação entre a Matemática e a língua materna, áreas que aparentemente são consideradas desconectadas em conteúdos e metodologias.

Em particular, existem gêneros textuais na metodologia da língua materna que podem contribuir para melhorar a compreensão dos alunos diante de desafios e situações-problema em Matemática. 
Este texto objetivou verificar se alunos ingressantes de um curso de Licenciatura em Ciências manifestam evolução de estratégias diante de um problema matemático proposto na forma de um desafio, enunciado em um contexto de narrativa.

\section{A Narrativa e a Resolução de Problemas}

Na Matemática, a pesquisa em resolução de problemas é um campo que concentra muitos estudos, como em Borralho (1994), Schoenfeld (1997), Pozo (1998), Echeverría e Pozo (1998), Vieira (2001), Van de Walle (2001) e Polya (2006).

Para Van de Walle (2001), "problema" se define como qualquer tarefa ou atividade na qual os estudantes não têm métodos, regras prescritas ou não percebem que há um método específico para se chegar à solução correta.

Os autores Echeverría e Pozo (1998) concebem problema como uma situação diferente, difícil ou surpreendente, em que o indivíduo está inserido em um contexto de obstáculo, pois ainda não dispõe de um caminho rápido e eficiente que permita encontrar a(s) solução(ões), o que requer do sujeito a atitude de investigação e tomada de decisão.

Uma questão que tem sido tratada no tema de resolução de problemas é que esta área pode e deve propiciar ao estudante o desenvolvimento de capacidades cognitivas, metacognitivas e afetivas, que se constituem em importantes aspectos para a formação educacional na escolaridade básica e superior.

$\mathrm{Na}$ área de resolução de problemas matemáticos, Borralho (1994) pondera que nos aspectos afetivos destacam-se a pressão, a motivação, o interesse, os possíveis bloqueios, a perseverança, a idade biológica, a série escolar, a familiaridade com o tema, entre outros.

Quanto aos aspectos cognitivos, o autor destaca o lidar com o contexto e o conteúdo inerentes ao problema, a capacidade espacial, a lógica, a leitura e interpretação dos enunciados, bem como as possíveis estratégias envolvidas na busca da(s) solução(ões). 
Pozo (1998) destaca que a resolução de problemas permite estimular nos alunos a busca, a evolução e a apropriação de estratégias, não somente quanto aos exercícios escolares, mas especialmente quando associadas a situações variáveis e contextos cotidianos.

Schoenfeld (1997) complementa o entendimento sobre a resolução de problemas colocando-a como um processo que ajuda ao aluno a entender o enunciado de um problema, assim como dirigir seus recursos para resolvê-lo por meio do aprimoramento de heurísticas ou estratégias, para o alcance da(s) resposta(s).

Na posição de estimular o uso de heurísticas na resolução de problemas, torna-se importante situar um ambiente de interrogações, conjecturas, troca de ideias com colegas, para questionar e interagir com o meio, fatores que podem estimular o aluno a perceber e evoluir as próprias estratégias, o que requer fazer presente o recurso da metacognição.

Para Borralho (1994), a metacognição designa a capacidade de um indivíduo em saber administrar ou gerir uma tarefa, de modo a se autorregular, controlar, monitorar e se avaliar nas ações cognitivas e afetivas, em determinada atividade.

Alves e Da Luz (2007) ponderam que as capacidades metacognitivas relacionam-se aos conhecimentos que o estudante possui, como descreve e toma consciência dos seus próprios pensamentos, como se regula perante o que está por fazer, assim como o que o conduz às ações na resolução de problemas de Matemática.

Vieira (2001) acrescenta que a metacognição é o conhecimento que o sujeito possui sobre suas próprias forças e limitações. O autor ressalta que os bons resolvedores de problemas matemáticos sabem escolher o melhor entre os vários caminhos para a solução de um problema, assim como abandonar dados ou opções que pouco têm a oferecer. 
Alves e Da Luz (2007) argumentam que, em geral, as dificuldades surgidas durante a resolução de problemas não se originam da falta de conteúdo, mas sim por dificuldades do estudante em mobilizar o pensamento matemático, expresso em termos de estratégias, que o impedem de ter iniciativa e utilizar a capacidade de raciocinar.

Outro motivo apontado pelos referidos autores é a falta de compreensão estrutural da linguagem contida no enunciado do problema, que pode levar o resolvedor a uma representação mental insuficiente ou inadequada.

Neste ponto, temos por hipótese que o uso de narrativas em enunciados de problemas matemáticos pode favorecer uma maior compreensão do enunciado, assim como promover o uso e evolução de diversas estratégias de resolução, inserindo o aluno na necessária atitude de mobilização para se regular e se monitorar na busca de soluções.

Conforme Machado (2004), o uso da narrativa constitui-se em importante elemento de composição de atividades, constituindo uma competência básica e necessária para o professor de Matemática compor o repertório de ações didáticas.

A retórica estava presente em muitas civilizações antigas, como a egípcia, a hindu e a árabe. Historicamente, diante das diferentes situações pragmáticas que permitiram evoluir e construir o conhecimento matemático, Lorenzato (2006) relembra que os antigos povos geralmente expunham a(s) solução(ões) na língua corrente da época.

Vieira (2001) afirma que os primeiros estudos envolvendo a narrativa são devidos a Aristóteles, na obra Poética, em cerca de 335 a.C. A origem etimológica destaca que o termo deriva do verbo narrare (latim), que significa o ato de "[...] expor minuciosamente, contar, relatar, registrar, historiar", conforme descreve Aurélio Ferreira (2003). 
Aprofundando o tema, Bremond (1966 apud Vieira, 2001) propõe que os enunciados narrativos possuem uma lógica de possibilidades, situando o encadeamento das ações em uma estrutura triádica, em que a natureza cronológica da história pressupõe que um evento tenha início, se desenvolva e termine, segundo uma relação do consequente ao antecedente.

Para Labov e Waletzky (1967 apud Vieira, 2001), a narrativa comporta e necessita de uma dimensão figuracional. Nesse modo, há uma ordenação de elementos segundo a estrutura: orientação, complicação, ação ou avaliação, resolução, conclusão ou moral. Nesta estrutura se agrupam as proposições, estas constituindo as menores unidades da narrativa.

Um texto na forma narrativa inicia-se a partir de

[...] uma Orientação na qual são definidas as situações de espaço, tempo e características das personagens. Em seguida, ocorre uma Complicação através de uma ação que visa modificar o estado inicial e que dá início à narrativa propriamente dita. A narrativa, então, culmina no momento em que uma Ação transforma a nova situação provocada pela complicação ou em que uma Avaliação da nova situação indica as reações do sujeito do enunciado. A narrativa, então, chega a um Resultado em que é estabelecido um novo estado, diferente do estado inicial da estória. O final da narrativa se dá no momento em que é elaborada uma Moral, a partir das conseqüências da estória (VIEIRA, 2001, p. 202).

Labov e Waletzky (1967) definem narrativa como “[...] uma seqüência de duas proposições restritas, temporalmente ordenadas, de maneira que uma mudança em sua ordem resultará na mudança na seqüência temporal da interpretação semântica original" (p. 27 apud VIEIRA, 2001, p. 201).

Metz (1977 apud CRUZ, 2005) complementa que a narrativa é um tipo de discurso cuja função é transpor um tempo ou espaço, em que a história inerente ao discurso narrativo favorece a motivação e a compreensão, que atuam como instrumentos no campo educativo. 
Desse modo, a narrativa não se reduz a uma forma de apresentação literal de fatos, mas é transformadora de alguma realidade. As narrativas são formas de histórias que possuem várias funções, exercendo influência na formação cognitiva, afetiva e social

[...] das crianças, seja na forma de antigas lendas, contos de fadas, histórias infantis ou parábolas bíblicas. Independentemente do gênero, as narrativas de ficção valorizam e ampliam nossa capacidade imaginativa, desenvolvem várias habilidades e estruturas do pensamento, além de auxiliarem na construção de significados (DALCIN, 2002, p. 60).

As narrativas permitem transformar a virtualidade do pensamento para o plano da palavra falada ou escrita. A narrativa é uma forma de organização de acontecimentos ou fatos, não só a partir da manifestação do fluxo do pensamento verbalizado, mas pela formação de imagens mentais, o que pode prover um significado pessoal.

\begin{abstract}
Um atributo da imagem, dentre outros, é certa simultaneidade em sua apreensão, o que provém do fato dela ser um simulacro da Natureza; as palavras, no entanto, não são simulacros, elas substituem alguma coisa, tomam o lugar do objeto, possibilitando ao homem a socialização de suas percepções e sentimentos. As palavras se dão num encadeamento que permite a comunicação da experiência numa dimensão temporal que é muito menos evidente quando a mesma experiência é concebida figuralmente (CRUZ, 2005, p. 1).
\end{abstract}

Cruz (2005) destaca que as narrativas mobilizam a imagem e a palavra, o ícone e o signo, o imediato e o mediato, imbuídas em uma coordenação entre esses e outros elementos, de modo a tecer uma rede de significados, a serviço de uma intenção prévia, de uma ação a ser conduzida, o que possibilita uma ascensão do nível cognitivo do sujeito.

Para Castro (2014), narrar é derivado do adjetivo gnārus, referindo-se ao "que conhece ou sabe". A raiz deste adjetivo remonta ao indo-europeu "gno" (conhecer) e ao verbo latino "nōsco", indicando "começar a conhecer, aprender a conhecer", ainda identificável no grego "gnôsis" (ação de conhecer, conhecimento, ciência, sabedoria). 
Segundo Piletti (1999 apud Cruz, 2005), o verbo latino narrar tem o mesmo sentido do verbo alemão erfahren, denotando fazer conhecer, o que configura a experiência da narrativa como aquela que leva ao saber.

O estudo etimológico revela uma proximidade entre o narrar e o conhecer. Esta conexão pode ser percebida pela associação de uma dupla percepção oriunda das narrativas: a dos termos envolvidos e a da relação que os une num feixe de relações, que abre caminhos para a tecitura de significados dos conhecimentos.

Bruner (1987), em seus estudos, confere uma nítida ênfase à linguagem como o principal meio de representação simbólica da realidade, tanto concreta quanto abstrata. O ser humano constrói o conceito que adquire do mundo por meio dos "símbolos linguísticos" aos quais, gradualmente, vai atribuindo significados ao nível subjetivo e consensual.

O autor afirma que a narrativa permite negociar e renegociar os significados no contexto do desenvolvimento humano no viés filogenético e cultural. Bruner (1987) reafirma que o homem possui uma aptidão social para o significado, muito pela evolução da própria espécie humana (filogênese). Há uma função de apreensão do contexto, em que as regras sintáticas são apreendidas pelo uso, revelando uma função de instrumentalidade.

Culturamente, ela é enormemente auxiliada, é claro, pelos recursos narrativos armazenados por uma comunidade e, igualmente, por seu precioso kit de técnicas interpretativas: seus mitos, sua tipologia de compromissos humanos, mas também pelas suas maneiras tradicionais de delimitar e resolver narrativas divergentes (BRUNER, 1987, p. 65).

No campo do ensino, a riqueza dos elementos da narrativa empolga e configura um grau de proximidade com os personagens e o enredo, o que pode gerar a mobilização necessária dos alunos em aceitar os desafios propostos e enfrentá-los como se estes vivenciassem as situações, ato que Brousseau (1996) denomina "devolução". 
A seguir delineamos a metodologia de ordem qualitativa,${ }^{2}$ inspirada na Engenharia Didática, descrita em Artigue (1996), que consistiu na aplicação e análise de um problema matemático inserido na forma de um desafio, apresentado na forma de uma narrativa.

\section{A Metodologia da Pesquisa}

Machado (2002) faz referência a Douady (1993), autora que concebe a Engenharia Didática como uma sequência de aula(s) gestada(s) com a finalidade de realizar um projeto de aprendizagem a alunos, projeto este que evolui de acordo com as escolhas delineadas pelo professor-pesquisador e colocado em função dos comportamentos cognitivos dos alunos.

Artigue (1996) destaca que a Engenharia Didática objetiva estudar as relações entre a investigação e a ação no sistema de ensino. Metaforicamente, a metodologia inspirou-se na realização de um projeto pelo engenheiro, que aceita o controle científico, mas deve elevar a compreensão ao nível da enorme complexidade do campo didático.

A Engenharia Didática compreende quatro fases. A primeira fase é denominada de "Análises Preliminares", quando são feitas “[...] considerações sobre o quadro teórico didático geral e sobre os conhecimentos didáticos já adquiridos sobre o assunto em questão" (MACHADO, 2002, p. 201). Em nossa pesquisa situamos as dificuldades dos alunos e as contribuições envolvendo a resolução de problemas em conjunção com a narrativa.

Na segunda fase, conhecida como concepção e análise a priori, o “[...] investigador toma a decisão de agir sobre um determinado número de variáveis do sistema" (ARTIGUE, 1996, p. 202). Entre estas situamos as variáveis didá-

${ }^{2}$ Lüdke e André (1986) afirmam que a pesquisa qualitativa apresenta como características a coleta de dados situada no ambiente, pelo contato do pesquisador com a situação envolvida, de modo a dar maior atenção ao processo do que ao produto, dentro das perspectivas dos participantes. 
ticas, que remetem às escolhas que provocam modificações nas estratégias de resolução de problemas, de modo a permitir a evolução do desempenho cognitivo dos alunos (GÁLVEZ, 1996).

A terceira etapa, designada por experimentação, corresponde à aplicação da própria pesquisa a uma população de alunos e à coleta de dados.

A quarta fase corresponde à análise a posteriori e validação, quando ocorre o tratamento dos dados obtidos na experimentação, realizado por meio "[...] da confrontação entre as análises a priori e a posteriori, onde se validam ou se refutam as hipóteses levantadas no início da Engenharia Didática" (MACHADO, 1996. p. 208).

Inspiramo-nos nestas considerações para aplicar um problema matemático, na forma de um desafio, inserido em um contexto de narrativa. Este foi adaptado de uma pesquisa de mestrado que realizamos com alunos de Ensino Médio. Havíamos constatado uma grande dificuldade destes em compreender o enunciado e se mobilizar para a busca de soluções. Na ocasião os alunos participantes relataram que estranharam a forma de proposta do problema e tiveram dificuldade em apresentar algum tipo de solução. Somente uma dupla conseguiu esboçar uma solução parcial, mas não houve desenvolvimento na atividade, mesmo após a tentativa de intervenção do pesquisador.

Desse modo, nos questionando se tais resultados não poderiam se modificar com alunos do Ensino Superior, decidimos adaptar a proposta, de modo a diagnosticar o rol de estratégias disponíveis em alunos ingressantes do $1^{\circ}$ semestre de um curso de Licenciatura em Ciências, assim como criar uma ambientação que permitisse a evolução das estratégias, seja por meio da interação dos próprios alunos com o meio a-didático nas fases de ação, formulação ou validação, ou ainda por meio da dialética de institucionalização.

Segundo Brousseau (1996), o "milieu” ou meio a-didático é um sistema com intenção didática não explícita, sendo um obstáculo com resistência adequada para a introdução do jogo didático, possibilitando ações e retroações dos sujeitos, em uma atitude de reflexão para a criação de novos elementos para que o próprio aluno alavanque a aprendizagem. 
Para Brousseau (1996), o processo de aprendizagem contém quatro etapas: ação, formulação, validação e institucionalização. Nos esquemas de ação o aluno reflete, faz tentativas e uso de procedimentos de resolução, elegendo uma estratégia de base.

Nos esquemas de formulação, Brousseau (1996) destaca que há uma troca de informação entre o aluno (receptor) e o "milieu" (emissor), sem necessariamente haver uso explícito de linguagem matemática, podendo ocorrer ambiguidade, redundância, falta de pertinência ou eficácia na mensagem, dentro de retroações contínuas.

$\mathrm{Na}$ fase de validação espera-se que o aluno busque as provas necessárias para se situar em um debate social. Brousseau (1996) preocupa-se com aqueles alunos que não entram neste processo, pois pode ocasionar obstáculos didáticos, de modo que "[...] a validação não é, a priori, a melhor situação de aprendizagem de saberes" (p. 110), porém, a validação promove motivação, permite a exposição de pontos de vista, o aprender a escutar e ser escutado em grupo, assim como a respeitar a limitação epistemológica dos colegas.

Na etapa de institucionalização, Brousseau (1996) ressalta que o professor retoma explicitamente a ação, reconhecendo os conhecimentos relevantes obtidos pelos alunos, descartando outros desnecessários, ou ainda introduzindo o conhecimento almejado, o que permite revelar a ligação com os saberes já estabelecidos.

Em nossa situação, o "milieu” foi composto pelo enunciado do desafio, colocado na forma de um problema, dos conhecimentos prévios dos alunos e da possibilidade de troca de informações entre eles, assim como da lógica inerente à narrativa proposta, situados na ausência de intervenção explícita do pesquisador.

A atividade desta pesquisa foi proposta a alunos do $1^{\circ}$ semestre de um curso de Licenciatura em Ciências, de uma universidade pública, no Estado de São Paulo, durante o desenvolvimento de uma disciplina semestral do ciclo básico, comumente designada no meio universitário por Pré-Cálculo ou Fundamentos da Matemática, e que tem como meta oferecer uma revisão dos conhecimentos de Matemática Elementar. 
Dez alunos voluntários compareceram para participar da pesquisa, em um horário extra-aula, com duração de 1 hora. Antes de se iniciar a aplicação do desafio, foram explicados o objetivo e as condições da pesquisa, de modo a se obter o consentimento na participação. Na configuração da população presente decidimos dividir os alunos em cinco duplas, formadas por livre escolha dos participantes. As duplas foram designadas por $\mathrm{D}_{\mathrm{i}}$, com $1 \leq \mathrm{i} \leq 5\left(\mathrm{D}_{1}, \mathrm{D}_{2}, \mathrm{D}_{3}, \mathrm{D}_{4} \mathrm{e}\right.$ $\mathrm{D}_{5}$ ). Em cada dupla, os alunos foram designados por Aluno ${ }_{2 \mathrm{i}-1}$ e Aluno $_{2 \mathrm{i}}$ (Aluno 1 e Aluno 2, da dupla $\mathrm{D}_{1}$; Aluno 3 e Aluno 4 da dupla $\mathrm{D}_{2}$, e assim por diante).

Como investigador, assumimos o papel de observador e intervenção mínima, de modo a permitir as ações e retroações dos sujeitos da pesquisa, o mais independentemente possível, diante do desafio matemático proposto. A coleta de dados se constituiu por observações do pesquisador, pelo registro sonoro das manifestações e mediante produção escrita dos alunos, descrita nos denominados protocolos de pesquisa, de modo a ampliar as possibilidades de análise dos dados.

\section{Dinarlândia: A Análise a Priori}

A parte metodológica consistiu na aplicação de um desafio matemático, na forma de problema, embasado em um contexto de narrativa. Na Dinarlândia situaram-se como variáveis didáticas globais:

- a escolha de uma situação hipotética envolvendo somente cédulas de pequena ordem de grandeza para as transações comerciais;

- a proposta de um desafio, para estimular a reflexão, o levantamento de hipóteses, a tomada de decisão e o debate, por meio de propriedades dos números;

- a escolha de uma narrativa, que propiciasse ao aluno uma situação fictícia, cujo contexto criasse ambientação para se desvincular das cédulas usualmente utilizadas, o que possibilitaria um repensar da realidade cotidiana.

A seguir apresentamos o enunciado da $1^{\mathrm{a}}$ parte (ver Quadro 1). 
Quadro 1 - Dinarlândia - Parte 1

Em um reinado distante, de regime monarquista parlamentarista, existem cédulas de 1, 2, 5, 10, 20, 50 e 100 dinares circulando, que permitem pagar e receber troco nas transações monetárias usuais. $\mathrm{O}$ rei, excêntrico por natureza, resolveu, por decreto, extinguir as cédulas existentes, retirando-as de circulação. Então, instituiu operações de pagar e receber troco, somente com novas cédulas de 4 e 6 dinares.

I - O primeiro-ministro discorda do rei, argumentando que a utilização de cédulas de 4 e 6 dinares é imprópria. Cada grupo deve escrever um texto (uma declaração), embasada em algum argumento, de natureza matemática, mostrando se o grupo concorda ou discorda do primeiro-ministro.

Fonte: Adaptado de Pommer (2008, p. 87).

A parte 1 do desafio foi planejada para que o aluno pudesse utilizar a paridade, o múltiplo ou o divisor como uma estratégia alternativa. A escolha das cédulas do enunciado da narrativa intentou remeter à propriedade: a adição ou subtração de dois números pares resulta par, assim como qualquer combinação envolvendo os múltiplos destas cédulas.

O questionamento do primeiro-ministro visou a promover a reflexão sobre a quantidade de cédulas que poderiam ser utilizadas nas operações usuais de "dar" e "receber" troco. Previmos que alguns alunos concluiriam pela impossibilidade das cédulas propostas pelo rei, comprovando que o primeiro-ministro está certo.

As variáveis didáticas locais envolvidas foram as cédulas de 1, 2, 5, 10, 20, 50 e 100 dinares, no enunciado do problema, e as novas cédulas de 4 e 6 dinares, que impossibilitam o pagamento de quantias ímpares.

Descrevemos, a seguir, as possíveis estratégias que os alunos poderiam utilizar:

$\mathbf{E}_{\mathbf{1}}$ : Tentativa e erro, em que o aluno testa algumas possibilidades, por meio de cálculos.

$\mathbf{E}_{2}$ : A utilização do conceito de múltiplo de 2 ou paridade. 
$\mathbf{E}_{3}$ : A escrita da equação $4 \mathrm{x}+6 \mathrm{y}=\mathrm{n}$, com 'n' natural (não nulo), para justificar a impossibilidade da obtenção de valores inteiros impares não negativos.

O enunciado da parte 2 do desafio considerou o seguinte texto (Quadro 2):

$$
\text { Quadro } 2 \text { - Dinarlândia - Parte } 2
$$

O rei, descontente com seu primeiro-ministro, mas não podendo
demiti-lo por causa disso, resolve estabelecer um duelo a nível nacional para
resolver a questão de quais deveriam ser as duas moedas nacionais. Com este
concurso, o rei pretende desacreditar o primeiro-ministro, comprovando o
mérito de seu decreto anterior. O rei assim proclama:
"Hoje e somente hoje, abro inscrições para os súditos reais que de-
sejam colaborar com o Tesouro Nacional. Será paga a quantia de cem mil
dinares ao(s) súdito(s) que me mostrar(em) quais são as maneiras que podem
ser estabelecidas as duas cédulas necessárias para dar ou receber qualquer
quantia monetária em dinares. Ainda, dentre as várias maneiras, o(s) súdito(s)
deverá(ão) argumentar qual seria a mais cabível dentre todas, de modo a
promover o bem-estar monetário da nação. A regra única é que as cédulas
deverão ser números naturais menores que 6 . A única exceção desta regra é
a impossibilidade de emissão de cédula de 1 dinar".
Como súdito, cada grupo está convocado a procurar e expor uma
solução.

Fonte: Adaptado de Pommer (2008, p. 87)

Na parte 2 do desafio caberia aos alunos descobrir duas cédulas que permitissem efetuar todos os pagamentos, nas condições proclamadas. $\mathrm{O}$ conceito de paridade, múltiplos ou divisores deveria ser a estratégia preferencial para a busca da solução.

As variáveis didáticas locais envolvidas, na parte 2 do desafio foram os valores das cédulas, menores que 6 dinares, que visou a restringir os cálculos e estimular reflexões em relação às possíveis combinações, assim como as cinco possíveis soluções. 
Descrevemos, a seguir, as possíveis estratégias que os alunos poderiam utilizar:

$\mathbf{E}_{\mathbf{1}}$ : Tentativa e erro, em que o aluno testa possibilidades, por meio de cálculos.

$\mathbf{E}_{2}:$ Utilização de propriedades dos números inteiros.

$\mathbf{E}_{3}:$ O equacionamento $\mathbf{a x}+\mathbf{b y}=\mathbf{c}$, com parâmetros inteiros não negativos, para se justificar quais valores inteiros não negativos de "a" e "b" são possíveis.

Os alunos deveriam decidir quais combinações de cédulas poderiam ser utilizadas: ambas pares, que não resulta em pagamento de quantias ímpares; par e ímpar, ou ambas ímpares, que permitiriam pagar em dinheiro qualquer quantia. As combinações possíveis de notas (em dinares) são: 2 e 3; 2 e 5; 3 e $4 ; 3$ e $5 ; 4$ e 5 .

\section{A Aplicação e a Análise a Posteriori da Engenharia Didática}

Após a leitura da parte 1 da Dinarlândia, realizada por todos os grupos, os alunos redigiram argumentação por escrito. As respostas dos grupos foram representadas no Quadro 3. 
Quadro 3 - Resolução da Atividade Dinarlândia - Parte I

\begin{tabular}{|c|c|c|}
\hline & Posição & Argumentos \\
\hline $\mathrm{D}_{1}$ & $\begin{array}{l}\text { Concordam com } \\
\text { o } 1^{\circ} \text { ministro }\end{array}$ & 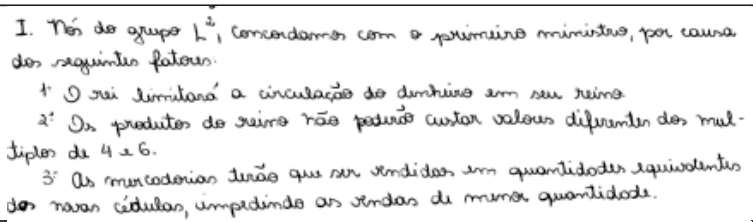 \\
\hline $\mathrm{D}_{2}$ & $\begin{array}{l}\text { Concordam com } \\
\text { o rei }\end{array}$ & $\begin{array}{l}\text { A ceduca de } 4 \text { e } 6 \text { diliares fulucioluariam, porem, on pregos } \\
\text { Teriamqueser asusrado para que fossom unmeros Inteiros }\end{array}$ \\
\hline $\mathrm{D}_{3}$ & $\begin{array}{l}\text { Concordam com } \\
\text { o } 1^{\circ} \text { ministro }\end{array}$ & a) náo é possível "lazer opepat, \\
\hline $\mathrm{D}_{4}$ & $\begin{array}{l}\text { Concordam com } \\
\text { o } 1^{\circ} \text { ministro }\end{array}$ & 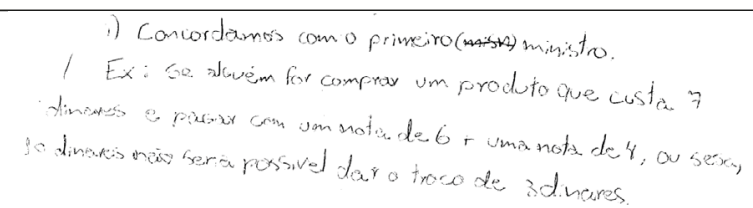 \\
\hline $\mathrm{D}_{5}$ & $\begin{array}{l}\text { Concordam com } \\
\text { o } 1^{\circ} \text { ministro }\end{array}$ & 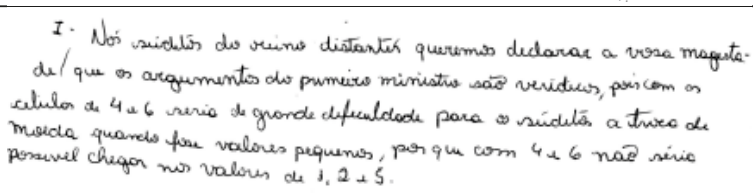 \\
\hline
\end{tabular}

Fonte: $\mathrm{O}$ autor.

As duplas $\mathrm{D}_{4}$ e $\mathrm{D}_{5}$ utilizaram a estratégia $\mathrm{E}_{1}$, ou seja, por tentativa e erro foram testadas várias possibilidades para a busca dos possíveis valores de pagamento, utilizando cálculos mentais ou explícitos, indicando alguns casos particulares.

A dupla $\mathrm{D}_{2}$ concordou com o rei, argumentando que os preços teriam de ser ajustados para números naturais, de modo a que pudessem ser adaptadas as cédulas de 4 e 6 dinares!

Verbalmente, esta dupla argumentou: "Para uma nota de dois dinares o esquema funcionaria assim: se eu desse uma nota de seis, eles me devolveriam uma nota de quatro. E, assim se daria para outros casos. Também, caso um produto custasse 1 [dinar], a pessoa teria que comprar mais produtos, para que fosse possível utilizar as cédulas". 
Questionamos a dupla $\mathrm{D}_{2}$ sobre outros exemplos que pudessem validar esta afirmação, porém a resposta foi que não haviam pensado nisto. Voltei a indagá-los se a enunciação de somente um argumento seria suficiente para justificar uma proposição. A referida dupla fez somente gestos e não quis se manifestar, mesmo após uma nova solicitação feita pelo pesquisador com relação a explicar, de novo, a última ponderação.

A dupla $\mathrm{D}_{3}$ fez uso implícito da estratégia $\mathrm{E}_{2}$, ou seja, que a paridade tem influência, argumentando que com as cédulas de 4 e 6 não é possível pagar quantias ímpares.

Situação análoga ocorreu com a dupla $\mathrm{D}_{1}$, pelo comentário que fizeram, em que as trocas se limitavam aos preços dos produtos que sejam múltiplos das cédulas de 4 e 6 dinares. Este argumento é parcialmente incorreto, pois não considera que é possível pagar, por exemplo, 2 dinares ou 14 dinares, dentre outros valores, que não são múltiplos de 4 ou de 6 .

Após a manifestação das cinco duplas, procedemos à entrega da folha com o enunciado da parte 2 da Dinarlândia. As respostas das duplas estão representadas no Quadro 4. 
Quadro 4 - Resolução da Atividade Dinarlândia - Parte 2

\begin{tabular}{|c|c|}
\hline & Argumentos dos alunos \\
\hline $\mathrm{D}_{1}$ & 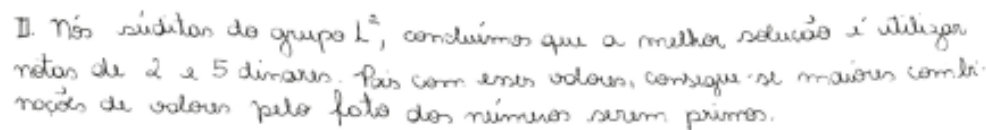 \\
\hline $\mathrm{D}_{2}$ & 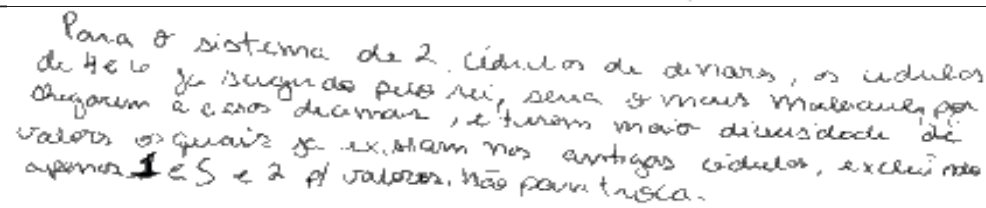 \\
\hline $\mathrm{D}_{3}$ & 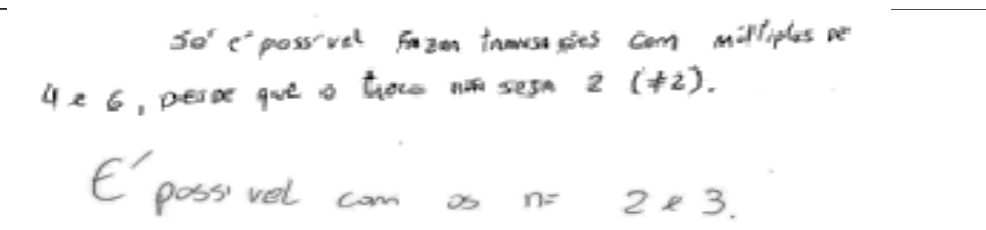 \\
\hline $\mathrm{D}_{4}$ & Resposta verbal: Utilizando as notas de 2.3 .5 e 7. \\
\hline $\mathrm{D}_{5}^{+}$ & 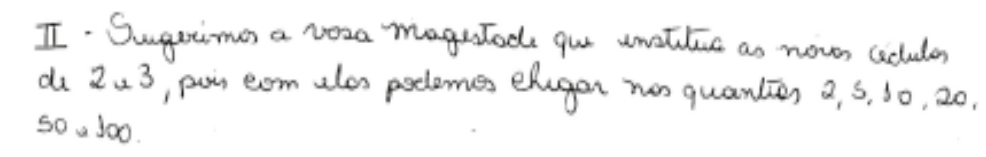 \\
\hline
\end{tabular}

Fonte: $\mathrm{O}$ autor.

As respostas indicaram que as duplas $\mathrm{D}_{3}$ e $\mathrm{D}_{5}$ manifestaram argumentação baseada em tentativa e erro, testando várias possibilidades para a busca de possíveis soluções utilizando cálculos mentais ou explícitos.

A dupla $D_{1}$ apresentou resposta correta, mas a justificativa não tem correspondência semântica com a afirmação. Quanto à dupla $\mathrm{D}_{4}$, esta não compreendeu que a escolha era para ser realizada com duas cédulas.

Quanto à dupla $\mathrm{D}_{2}$, que sempre concordou com o rei, as alunas não repensaram a resposta obtida na parte 1 da Dinarlândia. Deste modo, responderam que as cédulas deveriam continuar com os valores 4 e 6 dinares, apresentando argumentação inconsistente, pois desejam excluir transações monetárias de 1, 2 e 5 dinares, sem apresentar uma justificativa plausível para tal afirmativa. 


\section{A Validação e Institucionalização da Dinarlândia}

Após a etapa da ação e formulação, procedemos à etapa da validação, quando se abriu um debate mediado pelo pesquisador. A intenção era que cada grupo expusesse oralmente os resultados, de modo a possibilitar que os demais grupos se posicionassem.

Na sequência da pesquisa perguntamos se alguma dupla gostaria de comentar as respostas ou rever a posição adotada, porém nenhuma dupla se manifestou, mesmo após a insistência do pesquisador. Esta oportunidade se constitui em um mote para colocarmos algumas questões, abertas a todos, para provocar a manifestação dos alunos.

Pesquisador: As cédulas propostas na segunda parte da Dinarlândia poderiam ser de 3 e 5 dinares?

Alguns alunos responderam que sim e a dupla $\mathrm{D}_{2}$ continuou afirmando que não. Pesquisador: Então, dêem argumentos para que seja possível utilizar as cédulas de 3 e 5 ?

Após várias falas, um aluno responde:

Aluno 5: Com as cédulas de 3 e 5 se consegue dar e receber troco. Você dá duas notas de três e devolve uma nota de cinco.

Pesquisador: Duas de 3 e devolve uma de 5. Assim você consegue dar de troco 1 dinar. E como se faz para pagar outros valores, como, por exemplo, 2 dinares? Aluno 5: Dá uma de 5 e devolve uma de 3.

Pesquisador: Vocês estão utilizando exemplos particulares para justificar as afirmações. Como seria possível garantir, sem o uso da tentativa e erro, que é possível pagar qualquer quantia, por exemplo, com as cédulas de 3 e 5 dinares?

Aluno 5: Você escreve a equação $5 \mathrm{x}-3 \mathrm{y}=\mathrm{z}+1$

Pesquisador: E o que significam as letras $\mathrm{x}, \mathrm{y}$ e $\mathrm{z}$ ?

Aluno 5: "x" e "y" seriam as quantidades de cédulas de 3 e 5 dinares que estariam em jogo. Já o "z" seria o valor que eu desejaria obter. 
Pesquisador: Como assim, explique a função do "z" e por que " $z+1$ ”?

Aluno 5: Quando você dá duas notas de 3 e devolve uma nota de 5, o valor de z +1 seria 1 , o valor que eu devo pagar. Se eu usar outras quantidades de cédulas de 3 e 5 , o valor de $\mathrm{z}$ muda.

Aluno 3: No caso do exemplo dado, 5x-3y deve ser igual a um número inteiro, que é uma equação com duas variáveis, com os coeficientes 3 e 5.

Perguntamos se havia outras colocações sobre o uso de cédulas de 3 e 5 ou outras ponderações. Após um silêncio, tendo o fato de que as respostas estavam sendo dadas praticamente por somente um aluno, com uma rara intervenção de outro colega, resolvemos institucionalizar as conclusões até o presente momento. Assumimos esta posição pois, conforme aponta Brousseau (1996), na validação sempre há de ter uma preocupação com os alunos que não conseguem encontrar argumentos matemáticos válidos.

Ressaltamos que adaptamos a etapa de validação, proposta por Brousseau (1996), por nossa própria interpretação, acrescentando a possibilidade de provocar, a partir das próprias produções dos alunos, uma etapa dialogada que favorecesse o repensar dos procedimentos e escolhas realizadas, o que favorece aspectos ligados à metacognição.

Assim, passamos para a fase da Institucionalização. Nesta etapa partimos da colocação principalmente originada pelo aluno 5, argumentando que uma resposta matemática mais adequada seria $3 \mathrm{x}+5 \mathrm{y}=\mathrm{c}$, sem a necessidade de se adicionar o valor $1(\mathrm{c}+1)$. $\mathrm{O}$ termo "c" seria o valor da transação monetária a ser efetivada.

Comentamos que nada impediria de se utilizar o valor de " $z$ ", mas, historicamente, na fase simbólica, Fiorentini, Miorim e Miguel (1993) argumentam que Descartes (1596-1650) propôs que valores de variáveis fossem representados pelas últimas letras do alfabeto $(\mathrm{x}, \mathrm{y} \quad \mathrm{z}$...), e as iniciais $(\mathrm{a}, \mathrm{b} \quad \mathrm{c} \ldots)$ seriam utilizadas para as quantidades conhecidas, denominadas de parâmetros, padrão que perdura até hoje nos textos matemáticos. 
Também acrescentamos que outras soluções seriam cédulas de 2 e 3 dinares ou ainda de 2 e 5 dinares. Nesta etapa, para avaliar se a institucionalização estava surtindo efeito, voltamos a perguntar se eles tinham entendido que estas cédulas também poderiam ser utilizadas.

Um aluno respondeu que com as cédulas de 2 e 3 dinares poderia se pagar 1 dinar, pois bastaria tirar 3 de 2, assim como pagar 5. Outros alunos fizeram suas colocações, ainda se atendo a alguns exemplos numéricos particulares.

É de se notar que a preferência pelas tentativas numéricas ainda persiste, como foi o cenário de nossa pesquisa de mestrado com alunos do Ensino Médio. Isto enseja o pragmatismo das crenças dos alunos, que preferem resolver o problema pelo emprego da aritmética, ao invés do uso da escrita algébrica. Isso indica que a obtenção de resultados numéricos em problemas encontra-se desconectada do uso da escrita algébrica, de modo que as técnicas que eles conhecem para o tratamento algébrico não são transpostas para a resolução de problemas e desafios, a menos que se estabeleça uma forma de provocar tais usos.

Acreditamos, igualmente, que o uso de cálculos pelos alunos parece se constituir em um tipo de prova empírica, na qual eles têm necessidade de efetivar cálculos para compreender, iniciar o processo de resolução do problema e justificar questões. Assim, o recurso às provas e demonstrações matemáticas poderiam contribuir para a melhoria da percepção dos alunos quanto às diversas formas escritas da Matemática.

\section{Conclusões}

Dizer a um estudante que a resolução de problemas é uma atividade necessária não é um ato convidativo. É imperioso que o aluno sinta ímpeto de se envolver e trilhar o desejo de superar desafios que a área da Matemática poderia propiciar.

Machado (2009) ressalta que a multiplicidade de linguagens enriquece os canais de comunicação e permite uma abrangência de entendimento em temas da Matemática. Acreditamos que o exemplo de narrativa encenada no 
desafio "Dinarlândia" possibilitou aos alunos explorarem diversas estratégias de resolução e formas de representação - textual, aritmética e algébrica - de modo gradual, simples e acessível.

As manifestações verbais, aritméticas e, em alguns poucos casos algébricas, situaram uma exposição e evolução de estratégias, que permitiram aos alunos galgar níveis intermediários para a compreensão da importância e necessidade da escrita algébrica, o que situou uma forma alternativa de se aprimorar o pensamento algébrico.

A presente pesquisa indicou que os alunos precisam ser provocados para manifestar o que pensam, pois, em muitos casos da vida escolar, os alunos raramente trabalham com problemas, ainda mais quando se apresentam enunciados extensos, em que é requerida uma leitura mais atenta e uma participação mais ativa para a busca das soluções.

Esta possibilidade foi viabilizada pelo uso da metodologia inspirada e adaptada da Engenharia Didática, que se mostrou uma possível forma de organizar e gestar a aprendizagem dos assuntos, pelo confronto dos alunos com o "milieu", e ainda com uma intervenção mínima do pesquisador na etapa de validação.

Os resultados delineados no transcorrer da Dinarlândia permitiram observar que, para que os alunos percebessem o uso da escrita algébrica, tornou-se fundamental que eles, por si mesmos, pudessem expor alguns resultados numéricos, por tentativa e erro, refletissem sobre as questões propostas na narrativa e se posicionassem sobre o assunto utilizando argumentos aritméticos, situados nas fases de ação e formulação (Brousseau, 1996).

Ainda houve resistência dos alunos em se manifestar na etapa de validação, provavelmente oriunda de uma cultura em que o papel do aluno é passivo nas escolas brasileiras. Desse modo, tornou-se necessária uma forma de provocação, por parte do pesquisador. Mesmo assim, na validação houve manifestações de somente dois alunos, mas que fez emergir uma forma inicial de possibilidade de escrita algébrica. 
Acreditamos que a Dinarlândia situou um modo de vivenciar situações que permitem ao estudante exercitar a autorregulação, a agir com motivação, envolver-se com a tarefa, tomar decisões e agir com certa autonomia, aspectos estes reveladores do exercício da atitude metacognitiva, conforme destaca Borralho (1994).

Aliaram-se a estas considerações a possibilidade de acesso por uma abordagem que faz uso de algumas características do texto narrativo, conforme expõe Vieira (2001). Deste modo, os personagens (rei e primeiro-ministro) permitiram situar a complicação (a discordância do primeiro-ministro e o contra-argumento pela proclamação do desafio real), adentrar ao contexto das ações e resoluções dos súditos (alunos) para resolver os impasses criados, com o uso de linguagem matemática (verbal, aritmética ou algébrica), o que gerou a necessidade dos desdobramentos e a conclusão dos acontecimentos, propiciando um momento de aprendizagem, na conjunção da língua materna com a área da resolução de problemas matemáticos.

A composição de aspectos da Engenharia Didática com o desafio propiciado pela riqueza dos elementos da narrativa, empolgante, configuraram um grau de proximidade com os personagens e o enredo, o que favoreceu a mobilização dos alunos para aceitar e resolver os desafios propostos, enfrentando-os como se estes vivenciassem as situações, encenando o conceito de devolução de Brousseau (1996).

Tal afirmação revelou-se no protocolo do Quadro 4: "Nós, súditos do reino distante, queremos declarar a vossa majestade que os argumentos do primeiro-ministro são verídicos, pois com as cédulas de 4 e 6 dinares seria de grande dificuldade para os súditos a troca de moeda quando fossem valores pequenos".

Assim, a Matemática e a língua materna, áreas que aparentemente são consideradas antagônicas, possibilitaram uma imbricação pelo recurso de uma ferramenta do quadro linguístico - a narrativa - questão essencialmente ligada a um cenário de complementaridade, na área da Educação, destacado nos PCN (BRASIL, 1997). 
Conforme relata Cruz (2008), apesar de ser difundido que as narrativas auxiliam a construção de significados em Matemática, não basta que se conte qualquer história. É preciso a ação do professor para a escolha de situações que sejam impactantes e relevantes do ponto de vista educacional. "Não é propriamente o conteúdo que determina o sucesso de uma narrativa, mas o modo de contar. [...] Contar é uma arte e esta pode ser chamada de estilo" (CRUZ, 2008, p. 1).

\section{Referências}

ALVES, H. O.; DA LUZ, A. A. Aspectos cognitivos, metacognitivos e afetivos envolvidos na resolução de problemas matemáticos. Revista Contemporânea da Educação, v. 2, n. 3, 2007.

ARTIGUE, M. Engenharia Didática. In: BRUN, J. Didática das matemáticas. Tradução Maria José Figueiredo. Lisboa: Instituto Piaget, 1996. p. 193-217. Cap. 4.

BORRALHO, A. M. A. Aspectos metacognitivos na resolução de problemas de matemática: proposta de um programa de intervenção. 1994. Tese (Mestrado em Tecnologia da Educação) - Universidade de Évora, Associação de Professores de Matemática, Portugal, 1994.

BRASIL. Parâmetros Curriculares Nacionais: Matemática. Brasília: SEMT; MEC, 1997.

BROUSSEAU, G. Fundamentos e métodos da didáctica da matemática. In: BRUN, J. Didática das Matemáticas. Lisboa: Instituto Piaget, 1996. Cap 1, p. 35 -113.

BRUNER. S. J. O processo da educação. 8. ed. São Paulo: Companhia Editora Nacional, 1987.

CASTRO, N. J. Ciberdúvidas da Língua Portuguesa, 2014. Disponível em: <http://www. ciberduvidas.com/pergunta.php?id=29827>. Acesso em: 8 abr. 2014.

CRUZ, M. O. O estilo em matemática. São Paulo: Sema; USP, 2008.

. Narrativa e cinema: conexões com a aula de matemática. São Paulo: Sema; USP, 2005.

DALCIN, A. Um olhar sobre o paradidático de matemática. 2002. 162f. Dissertação (Mestrado em Educação Matemática). Faculdade de Educação, Universidade Estadual de Campinas, Campinas, 2002. Disponível em: <http://www.fae.unicamp.br/zetetike/ include/getdoc.php?id=121\&article=25\&mode=pdf $>$. Acesso em: 21 maio 2014 . 
D’AMBROSIO, B. S. Formação de professores de matemática para o século XXI: o grande desafio. Pro-Posições, Campinas, v. 4, n. 1/10, p. 35-41, mar. 1993.

ECHEVERRÍA, M. P. P.; POZO, J. I. Aprender a resolver problemas e resolver problemas para aprender. In: POZO, J. I. (Org.). A solução de problemas: aprender a resolver, resolver para aprender. Porto Alegre: ArtMed, 1998. p. 13-42. Cap. 1.

FERIGUETTI, K. M.; LUCAS, T. M. Onde está o problema para resolver problemas: capacidade leitora e linguagem matemática. In: CNEM, 2., Ijuí/RS, 2011.

FERREIRA, Aurélio Buarque de Holanda. Dicionário da Língua Portuguesa (Eletrônico). Rio de Janeiro: Editora Nova Fronteira, 2003. CDRoom.

FIORENTINI, D.; MIORIM, M. Â.; MIGUEL, A. Contribuição para um repensar ... a educação algébrica elementar. Pro-Posições, v. 4, n. 1, p. 78-91, mar. 1993.

GÁLVEZ, G. A didática da matemática. In: PARRA, C.; SAIZ, I. Didática da matemática: reflexões psicopedagógicas. Tradução Juan Acuña Llorens. Porto Alegre: ArtMed, 1996. p. 26-35. Cap. 2.

LIEL, C. C.; BORTOLI, G. Revisão de literatura na área de investigação em resolução de problemas de ciências e matemática. In: CNEM, 2., Ijuí/RS, 2011.

LORENZATO, S. Educação infantil e percepção matemática. Campinas: Autores Associados, 2006.

LÜDKE, M.; ANDRÉ, M. E. D. A. Pesquisa em educação: abordagens qualitativas. São Paulo: Ed. Pedagógica e Universitária, 1986.

MACHADO, N. J. Conhecimento e valor. São Paulo: Ed. Moderna, 2004.

. Linguagens e narrativas em educação matemática. In: SEMINÁRIO DE EDUCAÇÃO MATEMÁTICA, 2, São Paulo, 2009.

. Sobre livros didáticos: quatro pontos. Em Aberto, Brasília, ano 16, n. 69, p. 29-38, jan./mar. 1996.

MACHADO, S. D. A. Engenharia didática. In: MACHADO, S. D. A. (Org.). Educação matemática: uma introdução. 2. ed. São Paulo: Educ, 2002. p. 197-208.

PASSOS, C. L. B.; OLIVEIRA, R. M. M. A. Investigando a construção e aplicação de narrativas para o ensino de matemática na formação de professores. In: REUNIÃO ANUAL DA ANPEd, 28, 2005. Anais eletrônicos... GT-19: Educação Matemática. Disponível em: <http://www.anped.org.br/reunioes/28/inicio.htm>. Acesso em: 12 jun. 2014.

POLYA, G. A arte de resolver problemas. Rio de Janeiro: Ed. Interciência, 2006.

POMMER, W. M. Equações diofantinas lineares: um desafio motivador para alunos do Ensino Médio. 2008, 153f. Dissertação (Mestrado em Educação Matemática) - São Paulo, PUC, 2008. 
POZO, J. I. (Org.). A solução de problemas: aprender a resolver, resolver para aprender. Porto Alegre: ArtMed, 1998.

SCHOENFELD, A. H. Heurística na sala de aula. In: KRULIK, S.; REYS, R. E. A resolução de problemas na matemática escolar. São Paulo: Atual, 1997. p. 13-31.

VIEIRA, A. G. Do conceito de estrutura narrativa à sua crítica. Psicologia: Reflexão e Crítica, 14(3), p. 599-608, 2001.

VAN DE WALLE, J. A. Elementary and Middle School Mathematics, 4. ed. Nova York: Longman, 2001. 